\title{
Avaliação morfológica e por imagem radiográfica da matriz óssea mineralizada heteróloga fragmentada e metilmetacrilato, preservados em glicerina para reparação de falhas ósseas em tíbias de coelhos ${ }^{1}$
}

\author{
Silvio H. de Freitas ${ }^{2 *}$, Renata G.S. Dória ${ }^{3}$, Fábio de S. Mendonça ${ }^{4}$, Lázaro M. de Camargo ${ }^{2}$, \\ Cristiano I. Presser ${ }^{5}$, Marcelo D. dos Santos ${ }^{6}$, Antonio C. Shimano ${ }^{7}$ e Carlos E. Ambrósio ${ }^{8}$
}

\begin{abstract}
Freitas S.H., Dória R.G.S., Mendonça F.S., Camargo L.M., Presser C.I., Santos M.D., Shimano A.C. \& Ambrósio C.E. 2013. [Morphological evaluation and radiographic image of fragmented heterolog mineralized bone matrix and methylmethacrylate preserved in glycerin to repair osseous defects in tibias of rabbits.] Avaliação morfológica e por imagem radiográfica da matriz óssea mineralizada heteróloga fragmentada e metilmetacrilato, preservados em glicerina para reparação de falhas ósseas em tíbias de coelhos. Pesquisa Veterinária Brasileira 33(6):765-770. Departamento de Clínica e Cirurgia Veterinária, Faculdade de Medicina Veterinária, Universidade de Cuiabá, Av. Antártica 788, Casa 26, Ribeirão da Ponte, Cuiabá, MT 78040-500, Brazil. E-mail: shfreitas@terra.com.br

The traumas that result in bone fractures, especially comminuted, have high importance in veterinary and human surgical routine. A $6 \mathrm{~mm}$ of segmental defect was performed at the medial metaphyseal region of the left tibia of 12 rabbits and an association of fragmented heterologue mineralized bone matrix and methylmethacrylate conserved in glycerin (98\%) was used as a graft to fill the bone defect. To evaluate the procedure morphological and radiological exams were performed after 30, 60, 90 and 120 days. There was gradual integration of the bone graft in the receptor bed in $100 \%$ of the cases showing that the material is biologically compatible as it promotes bone defect reparation without signs of infection, migration and/or rejection and can be considered one more option to be used as a substitute to fill bone defects.
\end{abstract}

INDEX TERMS: Biological and synthetic biomaterials, osseous integration, methylmethacrylate.

\footnotetext{
${ }^{1}$ Recebido em 16 de fevereiro de 2013.

Aceito para publicação em 7 de maio de 2013.

${ }^{2}$ Departamento de Clínica e Cirurgia Veterinária, Faculdade de Medicina Veterinária, Universidade de Cuiabá (UNIC), Av. Antártica 788, Casa 26, Ribeirão da Ponte, Cuiabá, MT 78040-500, Brasil. *Autor para correspondência: shfreitas@terra.com.br

${ }^{3}$ Departamento de Medicina Veterinária, Curso de Medicina Veterinária, Faculdade de Zootecnia e Engenharia de Alimentos (FZEA), Universidade de São Paulo (USP), Rua Duque de Caxias 225, Centro, Pirassununga, SP 13635-900, Brasil.

${ }^{4}$ Departamento de Morfologia e Fisiologia, Universidade Federal Rural de Pernambuco (UFRPE), Rua Dom Manoel de Medeiros s/n, Dois Irmãos, Recife, PE 52171-900, Brasil.

${ }^{5}$ Residente de Clínica Cirúrgica e Anestesiologia do Departamento de Clínica e Cirurgia, Faculdade de Medicina Veterinária, UNIC, Cuiabá, MT.

${ }^{6}$ Departamento de Reprodução, Faculdade de Medicina Veterinária, UNIC, Cuiabá, MT.

${ }^{7}$ Departamento de Biomecânica, Medicina e Reabilitação do Aparelho Locomotor, Faculdade de Medicina de Ribeirão Preto (FMRP), USP, Avenida Bandeirantes 3900, Monte Alegre, Ribeirão Preto, SP 14049-900, Brasil.

${ }^{8}$ Departamento de Medicina Veterinária, Curso de Medicina Veterinária, FZEA-USP, Pirassununga, SP.
}

RESUMO.- Os traumas que resultam em fraturas ósseas, principalmente as cominutivas, têm uma importância muito grande na rotina clínico-cirúrgica veterinária e humana. Foi realizada falha segmentar de $6 \mathrm{~mm}$ na região metafisária medial da tíbia esquerda de 12 coelhos, a qual foi preenchida com implante constituído de matriz óssea mineralizada heteróloga fragmentada e metilmetacrilato, preservados em glicerina (98\%) para a sua reconstrução. Foi realizada avaliação morfológica e radiológica aos 30, 60, 90 e 120 dias e observou-se a incorporação do implante ao leito receptor, em $100 \%$ dos casos, mostrando ser biologicamente compatível, pois promoveu a reparação das falhas ósseas, sem sinais de infecção, migração e/ou rejeição, sendo uma opção de substituto para preencher defeitos ósseos.

TERMOS DE INDEXAÇÃO: Biomateriais biológico e sintético, osteointegração, metilmetacrilato.

\section{INTRODUÇÃO}

Os traumas que resultam em fraturas ósseas, principalmente as cominutivas, têm uma importância muito 
grande na rotina clínico-cirúrgica veterinária. Da mesma forma, são frequentes afecções como a osteomielite, as não-uniões e/ou neoplasias ósseas, que necessitam de tratamentos ortopédicos reconstrutivos e de reposição de tecido ósseo (Ranzani et al. 1996, Rezende et al. 1998, Alievi et al. 2007). A melhor opção para tratar as falhas ósseas recai sobre o autoenxerto esponjoso, que consiste na remoção de tecido ósseo esponjoso do próprio paciente, sendo biologicamente compatível, acelerando a reparação óssea. No entanto, esse procedimento tem o inconveniente de aumentar a morbidade do paciente por lesar estruturas normais, causar dor, e prolongar o tempo anestésico e cirúrgico, além de não fornecer volume ósseo suficiente para reparar grandes falhas ósseas (Friedlaender 1982, Melo et al. 1998, Alievi et al. 2007, Freitas et al. 2008).

A fim de evitar os entraves inerentes ao autoenxerto, tem-se feito uso de biomateriais na reparação de falhas ósseas (Melo et al. 1998, Silva et al. 2003, Alievi et al. 2007). Os biomateriais são materiais não vivos, de origem biológica ou sintética, amplamente utilizados na área médica, que interagem com o sistema vivo e promovem respostas biocompatíveis (Turrer \& Ferreira 2008, Raposo-do-Amaral 2010). Os tecidos ósseos obtidos a partir de animais da mesma espécie, os aloimplantes, ou de espécies diferentes, os heteroimplantes, são biomateriais biológicos empregados na reparação de falhas ósseas com resultados satisfatórios (Lane \& Sandhu 1987, Ranzani 1996, Dasso et al. 1998, Morais et al. 2004, Freitas et al. 2006, Silva \& Mazzoneto 2006).

Com a utilização do implante de tecido ósseo obtido de espécies animais diversas à receptora, denominado heteroimplante, almeja-se um material biocompatível, não carcinogênico, atóxico, não antigênico e que não estimule processos inflamatórios, nem favoreça a infecção. Deve promover a osteoindução, que se dá pela formação de osso a partir de células osteoprogenitoras, oriundas das células mesenquimatosas primitivas sob a influência de um ou mais agentes indutores da matriz óssea, e a osteocondução que se caracteriza pelo crescimento ósseo por meio de aposição de tecido ósseo subjacente na presença de osso ou células mesenquimatosas indiferenciadas (Alexander 1987, Iamaguti et al. 1995, Melo et al. 1998, Akamoto \& Trento 2002, Alievi et al. 2007).

Associadas a estas propriedades reparadoras, a facilidade em se constituir um banco de ossos, amplia as possibilidades para utilização dos heteroimplantes, principalmente quando se tratar grandes perdas ósseas, devido à constante disponibilidade de tecidos (Melo et al. 1998, Freitas et al. 2012). Para isso, os tecidos ósseos devem ser coletados assepticamente, acondicionados e preservados em meio adequado, para que não se degenere, a fim de que suas propriedades osteoindutoras e/ou osteocondutoras sejam preservadas. As técnicas de preservação mais utilizadas para conservar tecidos ósseos são pelo uso de congelamento com nitrogênio, resfriamento, liofilização, autoclavagem, óxido de etileno, álcool 70\%, e glicerina $98 \%$, entre outros (Melo et al. 1998, Silva et al. 2003, Gutierres et al. 2006, Vilela et al. 2010).
Além dos biomateriais biológicos, as falhas ósseas também podem ser eficientemente reparadas por biomateriais sintéticos, com propriedades osteocondutoras, como sulfato de cálcio, vidros bioativos, fosfato tricálcico, hidroxiapatita, copolímero lacticoglicólico, metilmetacrilato, entre outros (Suominen et al. 1995, Rezende et al. 1998, Weinfeld et al. 1999, Moraes et al. 2004, Yacubian-Fernandes et al. 2004, Gutierres et al. 2006, Turrer \& Ferreira 2008, Alves et al. 2010, Marval et al. 2011, Spadeto Jr et al. 2011). Atualmente, o metilmetacrilato, por apresentar propriedades bioinertes, osteocondutoras, e por ser facilmente trabalhado e/ou moldado para obtenção de uma forma mais adequada ao leito receptor, tem sido amplamente utilizado na reparação de falhas ósseas extensas, tanto na medicina humana quanto na medicina veterinária (Bauer \& Muschler 2000, Yacubian-Fernandes et al. 2004, Raposo-do-Amaral et al. 2010).

A melhor opção para tratar e acelerar a cicatrização de pequenos defeitos ósseos seria com o uso de tecido ósseo autógeno. No entanto, nas grandes falhas ósseas, o seu uso torna-se limitado, pois aumenta a morbidade do paciente por comprometer tecidos normais, prolongar o tempo anestésico, pois necessita de dois procedimentos cirúrgicos, além de não fornecer volume ósseo suficiente. Logo, uma opção para atender essa demanda, seria o desenvolvimento de um implante constituído pela associação de biomateriais biológico (tecido ósseo heterólogo) e sintético (metilmetacrilato), que apresentasse propriedades osteogênicas, osteoindutoras e osteocondutoras, que não permitisse a colonização de bactérias, nem infecção, que proporcionasse resistência mecânica, fosse de fácil aquisição e baixo custo, e que não necessitasse de meio especializado para sua preservação (Friedlaender 1982, Melo et al. 1998, Khan 2000, Alievi et al. 2007, Turrer \& Ferreira 2008).

Tendo em vista a necessidade constante de reparar grandes perdas ósseas com substituto ósseo conveniente e adequado, o presente trabalho tem por objetivo avaliar, morfologicamente e por imagem radiográfica, o implante constituído por matriz óssea mineralizada heteróloga fragmentada (MOMHF) e metilmetacrilato, preservados em glicerina a 98\%, na reparação de falhas ósseas em tíbias de coelhos.

\section{MATERIAL E MÉTODOS}

Neste estudo foi confeccionado um implante para substituir falhas ósseas, utilizando-se da associação de matriz óssea mineralizada heteróloga fragmentada (MOMHF) e metilmetacrilato, ambos na mesma proporção. A MOMHF foi coletada assepticamente a partir de diáfise de tíbia de cães, clinicamente hígidos, com histórico de óbito por trauma. Para tanto, removeram-se os tecidos moles adjacentes à tíbia, as epífises e a medula óssea, sendo a diáfise coletada, lavada com solução salina $0,9 \%$ e acondicionada em glicerina a $98 \%$, em recipiente de vidro esterilizado, por um período não inferior a 30 dias, em temperatura ambiente. Para uso, a diáfise da tíbia foi hidratada em solução salina $0,9 \%$ por 10 minutos, em seguida, foi fragmentada em partículas de aproximadamente $2 \mathrm{~mm}$, utilizando-se de cizalha ortopédica e, posteriormente, desidratada em temperatura ambiente. Na sequência, esta MOMHF foi misturada, na mesma proporção, ao polímero de metilmetacrilato (pó), os quais foram adicionados ao monômero de metilmetacri- 
lato (líquido), até atingirem característica pastosa, quando foram moldados em um gabarito circular de $6 \mathrm{~mm}$ de diâmetro por $2 \mathrm{~mm}$ de espessura, dando origem ao implante, o qual foi acondicionado em glicerina a $98 \%$, por período não inferior a 30 dias.

Foram utilizados, como receptores, doze coelhos adultos, da raça Nova Zelândia, com peso médio de $3 \mathrm{~kg}$, distribuídos em quatro grupos de três animais: G30 (30 dias de pós-operatório), G60 (60 dias de pós-operatório), G90 (90 dias de pós-operatório) e G120 (120 dias de pós-operatório). Após jejum hídrico e alimentar de 2 horas, foi realizada, em cada coelho, tricotomia da região proximal medial da tíbia esquerda e anestesia dissociativa, pela associação de acepromazina $(0,1 \mathrm{mg} / \mathrm{kg})$ e tiletamina/zolazepam $(20 \mathrm{mg} / \mathrm{kg})$, via intramuscular, e bloqueio anestésico local infiltrativo com lidocaína 2,0\% $(0,4 \mathrm{~mL})$.

Na sequência, os animais foram posicionados em decúbito dorsal em calha metálica acolchoada, realizou-se antissepsia com povidona iodo, incisão sobre a pele, divulsão do subcutâneo e periósteo, exposição do córtex próximo-medial da tíbia esquerda. Com o uso de uma broca trefina acoplada a uma furadeira elétrica autoclavável de baixa rotação, criou-se uma falha óssea na tíbia dos coelhos (Fig.1A), pela remoção de um segmento corticoperiosteal de $6 \mathrm{~mm}$ de diâmetro. 0 defeito ósseo previamente criado foi preenchido com o implante preparado (Fig.1B), o periósteo e o subcutâneo foram aproximados com fio categute cromado 3.0, utilizando padrão de sutura contínua simples e a pele suturada com fio poliamida 3.0, com padrão de sutura simples separado. Os animais foram submetidos a cinco aplicações de enrofloxacina $(10 \mathrm{mg} / \mathrm{kg})$, via subcutânea, a cada 24 horas; três aplicações de cloridrato de tramadol ( $4 \mathrm{mg} / \mathrm{kg}$ ), via subcutânea, a cada 8 horas, e dois curativos diários com rifampicina sobre a ferida, até a retirada dos pontos, que ocorreu no décimo dia. No pós-operatório, os animais foram alojados individualmente em gaiolas, e em ambiente climatizado, alimentados com ração comercial e água $a d$ libitum.

As falhas ósseas implantadas e áreas adjacentes foram avaliadas radiograficamente $(50 \mathrm{~mA}, 0,04 \mathrm{~s}$ e $40 \mathrm{KV})$, na posição lateromedial, imediatamente após o procedimento cirúrgico (Fig.1C) e aos 30, 60, 90 e 120 dias do pós-operatório, visando acompanhar o comportamento do implante ao leito receptor.

Após cada tempo estipulado, 30, 60, 90 e 120 dias de pós-operatório, os animais foram eutanasiados, utilizando-se o protocolo anestésico previamente descrito, seguido de parada cardio-respiratória pelo uso de propofol e cloreto de potássio a $10 \%$, por via intravenosa. Ato contínuo, as tíbias esquerdas foram coletadas, os tecidos moles sobre o leito receptor removidos sendo, então, realizada osteotomia transversal na região central do implante-leito receptor (Fig.3A), com o uso de broca carbide cônica acoplada a uma caneta de alta rotação de um equipo odontológico. Na sequência, a superfície irregular dos cortes foram aplainadas com lixa d'água 2000 para realização da análise morfológica macroscópica.

\section{RESULTADOS}

Este estudo apresenta uma nova opção de substituto ósseo, biologicamente compatível, confeccionado a partir de dois biomateriais, sendo um biológico (MOMHF) e outro sintético (metilmetacrilato), para corrigir falhas ósseas em cirurgias ortopédicas reparadoras.

Todos os animais apoiaram o membro operado no pós-operatório imediato, demonstrando que a técnica cirúrgica empregada não comprometeu a estrutura física da tíbia, e as feridas cicatrizaram num período de dez dias, sem sinais que sugerisse infecção.

Observou-se, por meio de avaliações radiográficas, que os implantes estavam alojados em seus leitos receptores (G30; Fig.2A, G60; Fig. 2B, G90; Fig.2C e G120; Fig.2D), com ausência de proliferação e/ou lise óssea na interface implante-leito receptor. Não houve alterações nas densidades dos implantes, constituídos por áreas radioluscentes, correspondentes ao metilmetacrilato (seta branca), e áreas radiopacas, referentes à MOMHF (asterisco azul), desde sua implantação no leito receptor até os 120 dias (Fig.2A-D).

Aos 30 dias de pós-operatório (G30; Fig.2A), à avaliação radiográfica, notou-se pouca diferença em relação ao pós-operatório imediato, com pouca atividade óssea na interface implante-leito receptor de tíbias de coelhos. Aos 60 dias de pós-operatório (G60; Fig.2B), notou-se na interface implante-leito receptor de tíbias de coelhos presença de radiopacidade mais acentuada que nos animais do G30. Aos 90 dias de pós-operatório (G90; Fig.2C) nas interfaces do implante-leito receptor das tíbias dos coelhos notou-se radiopacidade superior quando comparada à dos animais do G60. Da mesma forma ocorreu aos 120 dias (G120; Fig.2D).

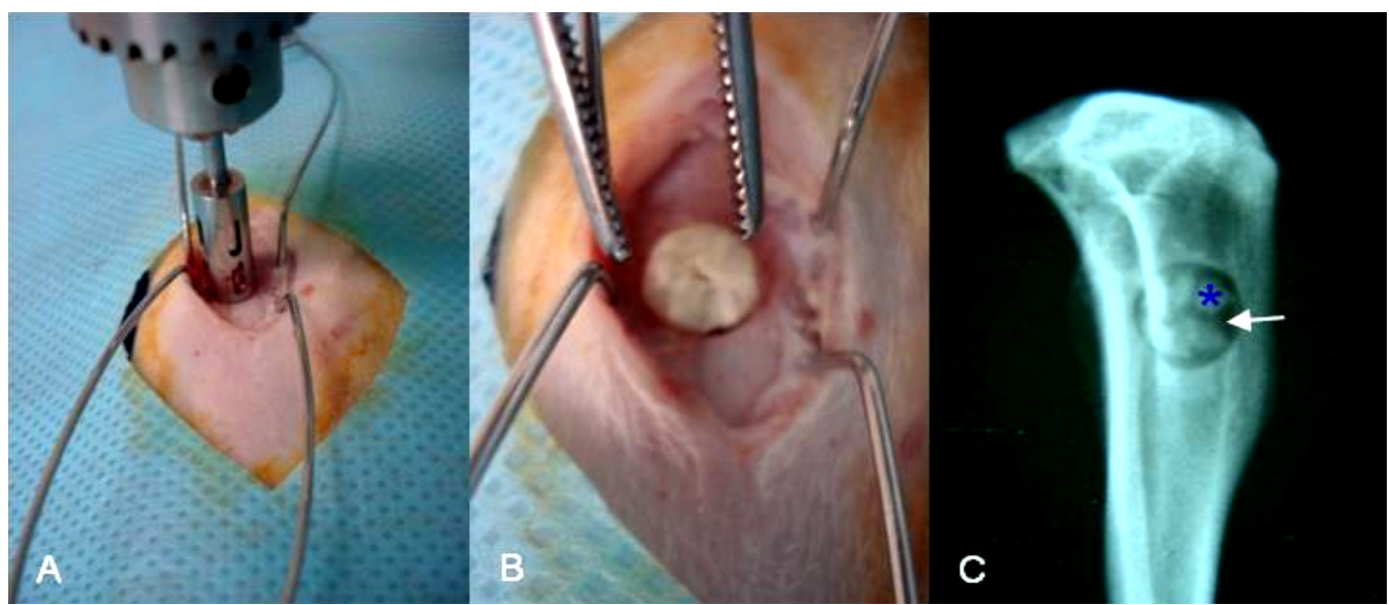

Fig.1. (A) Confecção do leito receptor com broca trefina, no córtex próximo-medial da tíbia esquerda de coelho. (B) Preenchimento do leito receptor com implante. (C) Imagem radiográfica no pós-operatório imediato. 


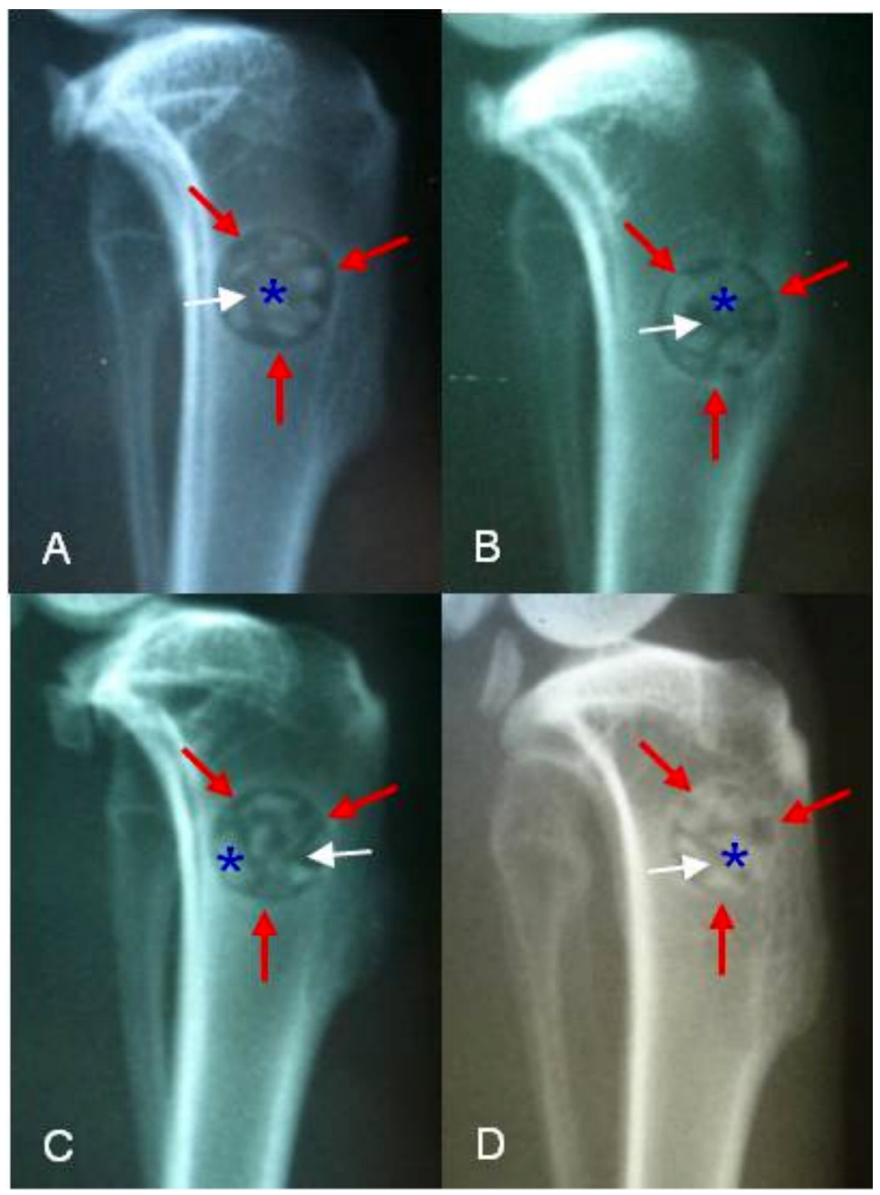

Fig.2. Imagem radiográfica lateromedial do terço proximal de tíbia esquerda de coelho. (A) Aos 30 dias, linha de interface bem definida entre o implante e leito receptor com discreta radiopacidade (setas vermelhas). (B) Aos 60 dias, linha de interface bem definida com leve radiopacidade (setas vermelhas). (C) Aos 90 dias, linha de interface com irregularidades e acentuada radiopacidade (setas vermelhas). (D) Aos 120 dias, linha de interface com irregularidades e elevada radiopacidade (setas vermelhas). Nota-se implante no leito receptor com áreas radiopacas (MOMHF - asterisco azul) e radioluscentes (metilmetacrilato - seta branca).

Não foram observadas reações na interface implante-leito receptor que caracterizassem lise e/ou proliferação óssea em nenhum dos tempos experimentais.

A avaliação morfológica macroscópica da interface implante-leito receptor foi possível pela realização da osteosseç̧ão com broca carbide cônica acoplada a uma caneta de alta rotação odontológica, para garantir a estabilidade do implante ao leito receptor.

A avaliação morfológica macroscópica aos 30 dias demonstrou que os implantes encontravam-se em seus leitos receptores, sem reação tecidual na interface implante-leito receptor. Aos 60 dias havia formação de tecido ósseo sobre a borda do implante em seu leito receptor (Fig.3A) e, ao corte transversal, notou-se que os implantes encontravam-se em contato e preenchiam os leitos receptores (Fig. 3B). Aos 90 dias, observou-se uma incorporação mais evidente dos implantes nos leitos receptores (Fig.3C) e ao corte transversal, verificou-se uma camada de tecido ósseo en- volvendo completamente a superfície externa do implante e, parcialmente, a superfície interna (Fig.3D). Aos 120 dias observou-se que os implantes preencheram e foram incorporados aos seus leitos receptores (Fig.3E). Ao corte transversal, verificou-se que todos os implantes estavam envolvidos por uma camada de tecido ósseo tanto pela superfície externa quanto pela interna (Fig.3F).

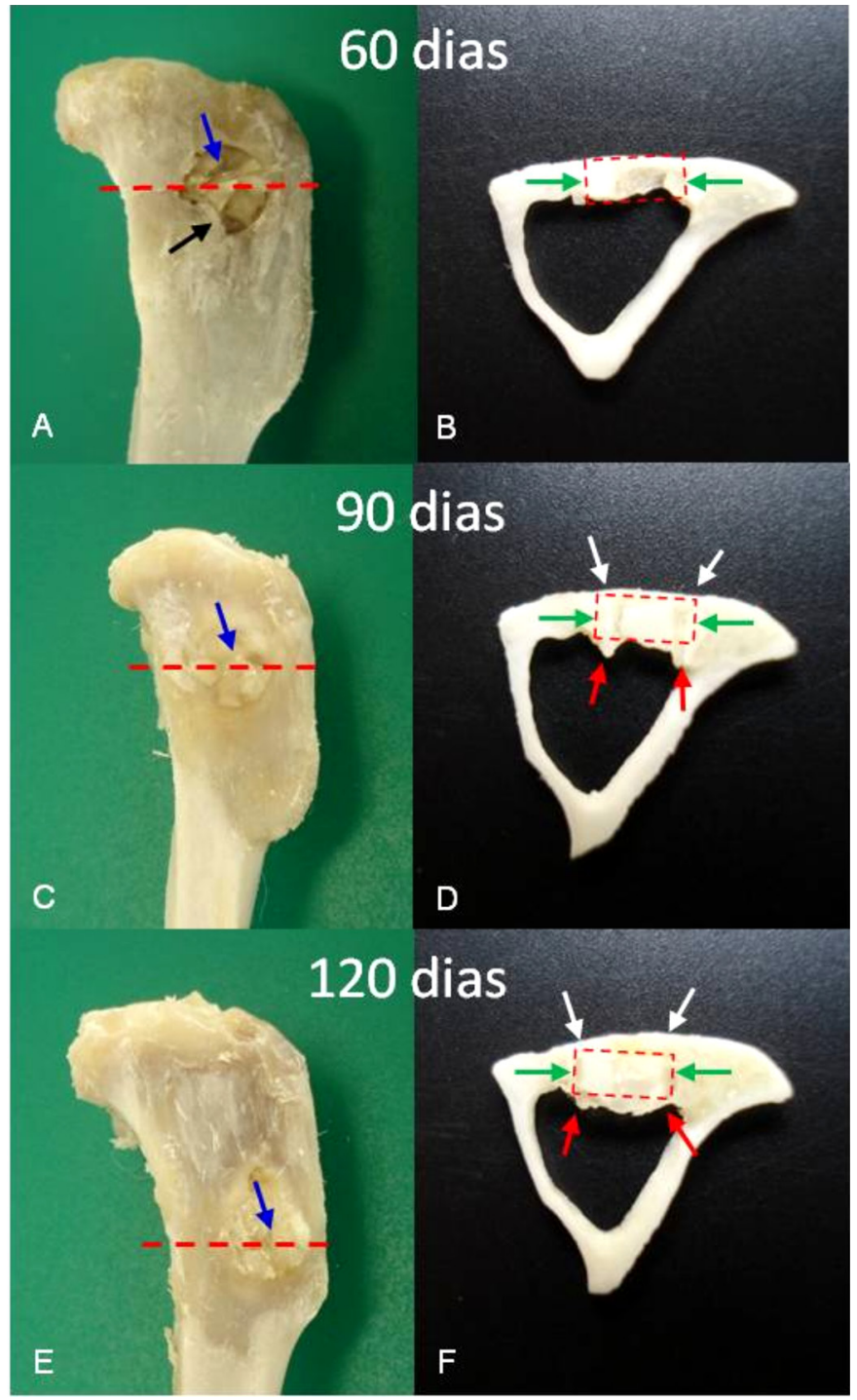

Fig.3. Superfície externa do implante no leito receptor e da secção transversal da tíbia esquerda dos coelhos. (A) Aos 60 dias, implante no leito receptor (seta azul) e presença de tecido ósseo sobre suas bordas (seta preta). (B) Implante preenchendo todo leito receptor (quadrado vermelho pontilhado), com ausência de lise óssea (setas verdes). (C) Aos 90 dias, implante incorporado ao leito receptor (seta azul). (D) Implante preenchendo todo leito receptor (quadrado vermelho pontilhado) e camada de tecido ósseo envolvendo toda superfície externa (setas brancas) e, parcialmente, à superfície interna (setas vermelhas), com ausência de lise óssea (setas verdes). (E) Aos 120 dias, implante incorporado ao leito receptor (seta azul). (F) Implante preenchendo todo leito receptor (quadrado vermelho pontilhado) e camada de tecido ósseo envolvendo completamente as superfícies externa (setas brancas) e interna (setas vermelhas), com ausência de lise óssea (setas verdes). 


\section{DISCUSSÃO}

Pesquisas utilizando biomateriais biológicos realizadas por Weinfeld et al. (1999) e Freitas et al. (2008) mostraram que o heteroimplante ósseo cortical (MOMHF) conservado em glicerina a 98\%, quando empregado na correção de falhas ósseas, são bem tolerados e promovem a reparação do defeito. Yacubian-Fernandes et al. (2004) e Raposo-do-Amaral et al. (2010) divulgaram em seus estudos que os biomateriais sintéticos, como o metilmetacrilato, são biocompatíveis e, também, podem ser empregados para corrigir grandes defeitos ósseos. Turrer \& Ferreira (2008) preconizaram que a associação de dois ou mais materiais de classes diferentes, como realizado neste estudo, apresentaria um melhor resultado quando empregado para tratar grandes falhas ósseas, pois, nesse caso, estaria adicionando as propriedades individuais desejáveis de cada um dos constituintes, tornando-o mais biocompatíveis, com menor possibilidade de falha e com propriedades superiores às dos componentes isolados.

Neste estudo, no pós-operatório imediato, todos os animais apoiaram o membro operado, demonstrando que a estrutura física da tíbia não foi comprometida pelo procedimento cirúrgico e que o controle da dor com analgésico foi eficiente (Melo et al. 1998). Todos os animais tiveram as feridas cicatrizadas em aproximadamente dez dias, sem sinais de reação tecidual e/ou infecção, demonstrando aceitação do implante ao leito receptor, elegendo a glicerina a 98\%, um meio seguro para conservar a MOMHF e o implante já preparado (Iamaguti et al. 1995, Freitas et al. 2012).

Embora haja questionamento quanto ao tempo mínimo e máximo que o tecido ósseo, para uso como implante, deva permanecer em glicerina a 98\%, Freitas et al. (2012) recomendaram que esse período não fosse menor que 30 dias, pois a eliminação de bactérias Gram negativas nesse meio pode levar até 27 dias. Sendo assim, a MOMHF empregada na confecção do implante, neste estudo, foi mantida nesse meio por período não inferior a 30 dias, momento em que foi utilizada e não foi observado sinais de infecção no foco cirúrgico, o que corrobora com os trabalhos previamente descritos (Melo et al. 1998, Del Carlo et al. 1999, Del Carlo et al. 2007, Freitas et al. 2008, Vilela et al. 2010). Além disso, neste estudo, os implantes antes de serem utilizados foram apenas reidratados em solução salina estéril, sem o uso de antibióticos, confirmando o efeito bactericida da glicerina a 98\%, uma vez que nenhum animal apresentou infecção da ferida cirúrgica. Demonstram-se, então, com este estudo, as propriedades conservadora e bactericida da glicerina a 98\%, associada à praticidade de uso e custo reduzido quando se compara aos demais processos de esterilização, como calor úmido (autoclave) ou seco (estufa), substâncias químicas (óxido de etileno) ou radiações ionizantes (radiação gama), reduzindo significativamente o ônus do procedimento cirúrgico como um todo (Vilela et al. 2010, Freitas et al. 2012).

O emprego da técnica radiológica, neste estudo, permitiu o acompanhamento com precisão do comportamento dos biomateriais no leito receptor das tíbias dos coelhos, configurando-se como um método confiável e eficiente para avaliar implantes em falhas ósseas em diferentes mo- mentos (Iamaguti et al. 1995, Silva et al. 2003, Freitas et al. 2008, Rocha et al. 2011). Por meio das avaliações radiográficas realizadas nas tíbias dos coelhos dos grupos G30, G60, G90 e G120, notou-se que todos os implantes permaneceram acomodados em seus leitos receptores, sem sinal de proliferação e/ou lise óssea, ou reações que caracterizassem infecção e/ou rejeição. Radiograficamente, foram observadas densidades heterogêneas de todos os implantes, constituídos por áreas radioluscentes, correspondentes ao metilmetacrilato (seta branca), e áreas radiopacas, referentes à MOMHF (asterisco azul), que permaneceram desde sua implantação no leito receptor até os 120 dias.

A interface implante leito-receptor, aos 30 dias, mesmo frente às propriedades osteoindutoras e osteocondutoras presente no implante (Silva, et al. 2003, Gutierres et. 2006, Turrer \& Ferreira 2008, Marval et al. 2011, Spadeto Jr et al. 2011, Freitas et al. 2012), demonstrou pouca atividade óssea, quando comparada radiologicamente ao pós-operatório imediato. Provavelmente, esse período não seja suficiente para que ocorra deposição de tecido ósseo local. No entanto, aos 60 dias de pós-operatório (G60) notou-se na interface do implante-leito receptor presença de radiopacidade mais acentuada que nos animais do G30, relacionada com a neoformação óssea sobre as bordas do implante, devido às propriedades osteocondutoras e osteoindutoras desse substituto ósseo. Da mesma forma, as interfaces do implante e leito receptor das tíbias dos coelhos aos 90 dias (G90) apresentaram radiopacidade superior quando comparada à dos animais do G60, assim como aos 120 dias (G120), quando observou-se intensa radiopacidade na interface entre o implante e o leito receptor, caracterizando incorporação e remodelação óssea (Turrer \& Ferreira 2008, Marval et al. 2011, Spadeto Jr et al. 2011, Freitas et al. 2012).

Morfologicamente não foram observados sinais nem reações que caracterizassem lise e/ou proliferações ósseas na interface implante-leito receptor, que sugerissem infecções e que pudessem comprometer a estabilidade do implante. Com essas características, o implante certamente poderá ser utilizado para preencher falhas ósseas em outras espécies como a canina e felina, já que apresentou propriedades osteoindutoras e osteocondutoras com resultados satisfatórios em defeitos ósseos em tíbia de coelho.

\section{CONCLUSÃO}

O comportamento do implante, constituído de matriz óssea mineralizada heteróloga fragmentada e metilmetacrilato, preservado em glicerina a 98\%, caracteriza-o como opção viável, prática e de custo reduzido na reparação de falhas ósseas, promovendo osteocondução e osteointegração, sem sinais de infecção e/ou rejeição, em tíbias de coelhos.

Comitê de Ética e Biossegurança.- Esta pesquisa foi aprovada pelo Comitê de Ética em Pesquisa da Universidade de Cuiabá-CEP/UNIC, sob o número 046, protocolo ${ }^{\circ}$ 2010-049, de 19 de abril de 2010.

\section{REFERÊNCIAS}

Akamoto T. \& Trento C.L. 2002. Implante homógeno de matriz dentinária desmineralizada conservada em glicerina a 98\% em alvéolo dental: estudo microscópico em rato. Revta Ciênc. Odont. 5:33-43. 
Alexander J.W. 1987. Bone grafting. Vet. Clin. North Am., Small Anim. Pract. 17:811-819

Alievi M.M., Schossler J.E.W., Guimarães L.D., Oliveira A.N.C., Traeslel C.K. \& Ferreira P. 2007. Implante ósseo cortical alógeno conservado em mel na reconstrução de falha óssea diafisária em fêmur de cães: avaliação clínica e radiográfica. Ciência Rural 37:450-457.

Alves E.G.L., Rezende C.M.F., Oliveira H.P., Borges N.F., Mantovani P.F. \& Rosado I.R. 2010. Emprego experimental da placa de compósito poli-hidroxibutirado/hidroxiapatita na fixação femoral em gatos. Arq. Bras. Med. Vet. Zootec. 62:1128-1134.

Bauer T.W. \& Muschler G.F. 2000. Bone Graft Materials. Clin. Orthop. 37:10-27.

Dasso G., Fernandez M.S. \& Arias J.L. 1998. Reparacion ósea mediante aloimplantes sometidos a diferentes métodos de conservación em conejos. Arch. Med. Vet. 30:57-66.

Del Carlo R.J., Galväo S.R., Viloria M.I.V., Souza T.D. \& Maia Filho A. 1999. Aloenxertos ósseos caninos diferentemente preservados. Revta Bras. Ciênc. Vet. 6:121-126.

Del Carlo R.J., Pinheiro L.C.P., Monteiro B.S., Silva P.S.A. \& Vianna V.W. 2007. Integração de aloenxertos ósseos corticais associados ou não à células-tronco da medula óssea, proteína óssea morfogenética (BMP) e autoenxerto esponjoso em cães. Vet. Zootec. 14:204-215.

Freitas S.H., Evêncio Neto J., Godoy R.F., Santos M.D., Rondon A.S. \& Camargo R. 2006. Aspectos radiográficos de implante ósseo heterólogo aplicado na metáfise proximal de tíbia de coelho. Anais 33o Congresso Brasileiro de Medicina Veterinária, Cuiabá, p.28. (Resumo)

Freitas S.H., Dória R.G.D., Mendonça F.S., Evêncio Neto J. \& Camargo L.M. 2008. Aspecto radiológico de heteroenxerto ósseo cortical fragmentado na reparação de falhas ósseas em coelhos. Revta Bras. Ciênc. Vet. 15:107-110.

Freitas S.H., Dória R.G.S., Mendonça F.S., Santos M.D., Moreira R., Simões R.S., Camargo L.M., Marques A.T.C. \& Simões M.J. 2012. Tomografia computadorizada da matriz óssea mineralizada heteróloga fragmentada e metilmetacrilato na reparação de falhas ósseas. Arq. Bras. Med. Vet. Zootec. $64: 1547-1554$

Friedlaender G.E. 1982. Current concepts review: bone banking. J. Bone Joint Surg. 64:307-311.

Gutierres M., Lopes M.A., Hussain N.S., Cabral A.T., Almeida L. \& Santos J.D. 2006. Substitutos ósseos: revisão. Arq. Med. 19:153-162.

Iamaguti P., Ineo A.P., Del Carlo R.J., Muniz L.M., Mamprim M.J. \& Dal Pai V. 1995. Uso de auto-enxerto ósseo esponjoso na reparação do rádio. Estudo experimental em coelhos. Vet. Zootec. 7:49-61.

Khan S.N. 2000. Clinical applications of bone graft substitutes. Orthop. Clin. North Am. 31:389-398.

Lane J.M. \& Sandhu H.S. 1987. Current approaches to experimental bone grafting. Orthop. Clin. North Am. 18:213-225.

Marval C.A., Alves G.E.S., Las Casas E.B., Costa C.G., Saffar J.M.E., Lago L.A., Carvalho W.T.V., Leal B.B. \& Faleiros R.R. 2011. Análise biomecânica ex vivo de um modelo de haste intramedular de polipropileno para osteossíntese em úmeros de bezerros. Arq. Bras. Med. Vet. Zootec. 63:273-278.
Melo E.G., Rezende C.M.F., Borges A.P.B. \& Nobrega Neto P.I. 1998. Aloenxerto ósseo cortical: avaliação do seu emprego em tíbia de cão. Arq. Bras. Med. Vet. Zootec. 50:385-394.

Moraes P.C., Padilha Filho J.G., Canola J.C., Santos L.A., Macoris D.G., Alessi A.C., Castro M.B. \& Dória Neto F. 2004. A Biocompatibilidade do cimento de fosfato de cálcio implantado no rádio de coelhos. Acta Cir. Bras. 19:351-359.

Ranzani J.J.T., Sampaio G.R., Franco M. \& Castro G.B. 1996. Aplicação de membrana biológica heteróloga conservada em glicerina, na reparação de lesão em coelhos. Vet. Zootec. 8:35-45.

Raposo-do-Amaral C.A.A., Raposo-do-Amaral C.E., Roland F.G., Silva J.V.L., Paschoal G.H.L. \& Silva A.M. 2010. Implantes pré-fabricados customizados nas grandes perdas ósseas do esqueleto craniofacial. Revta Bras. Cir. Craniomaxilofacial 3:175-179.

Rezende C.M.F., Borges A.P.B., Bernis W.O., Melo E.G. \& Nobrega Neto P.I. 1998. Aspecto clínico-cirúrgico e radiográficos da hidroxiapatita sintética na diáfise proximal da tíbia de cães. Arq. Bras. Med. Vet. Zootec. 50:537-545

Rocha F.S., Ramos L.M.A., Batista J.D., Zanetta-Barbosa D. \& Dechichi P. 2011. Organic bovine graft associated with prp in rabbit's calvaria. Intern. Arch. Otor. 15:208-213.

Silva A.M., Del Carlo R.J., Viloria M.I.V., Silva A.S. \& Filgueiras R.R. 2003. Matriz óssea homóloga desmineralizada na preparação de falhas ósseas segmentares produzidas no rádio de coelhos. Ciência Rural 33:539545 .

Silva F.M.S. \& Mazzoneto R. 2006. Avaliação clínica e histológica de enxerto ósseo bovino e proteína óssea morfogenética em levantamento de seio maxilar. Implant News 3:377-382.

Spadeto Jr O., Rodrigues L.B., Carvalho W.T.V., Moreira D.O., Marval C.A., Costa C.G., Alves G.E.S., Lascasas E.B. \& Faleiros R.R. 2011. Sistemas osso-implante ex vivo utilizando haste intramedular polimérica para imobilização de fraturas femorais em bovinos jovens. Ciência Rural 41:301-306.

Suominen E.A., Aho A.J., Juhanoja J. \& Yli-Urpo A. 1995. Hydroxyapatiteglass composite as a bone substitute in large metaphyseal cavities in rabbits. Inter. Orthop. 19:167-173.

Turrer C.L. \& Ferreira F.P.M. 2008. Biomateriais em cirurgia craniomaxilofacial: princípios básicos e aplicações: revisão de literatura. Revta Bras. Cir. Plást. 23:234-239.

Vilela L.M., Del Carlo R.J., Oliveira R.C., Rodrigues M.C.D., Monteiro B.S., Reis A.M.S. \& Machado D.P.D. 2010. Propriedades mecânicas de meniscos frescos de coelhos e preservados em glicerina 98\%. Ciência Rural 40:1114-1120.

Weinfeld I., Magalhães L.V. \& Vila N. 1999. Estudo histológico de um novo material (biobone) indicado para reparação óssea. Revta Paul. Odont. 21:9-10.

Yacubian-Fernandes A., Laronga P.R., Coelho R.A., Ducati L.G. \& Silva M.V. 2004. Prototipagem como forma alternativa para realização de cranioplastia com metilmetacrilato: nota técnica. Arq. Neuropatol. Psiquiatr. 62:865-868. 